\title{
Wishing to Feel Better... Perceptions of Health and IIIness in Persons with Rheumatic Diseases
}

\author{
Maria do Céu Sá \\ Escola Superior de Enfermagem de Lisboa (ESEL), \\ phD Student, at Universidade Católica Portuguesa (UCP), Lisboa, Portugal \\ Email: ceu.sa@esel.pt
}

\author{
Abílio Oliveira \\ Instituto Universitário de Lisboa (ISCTE-IUL), and Centro de Investigação em Sistemas \\ e Tecnologias de Informação Avançados (ADETTI-IUL), Lisboa, Portugal. \\ Author of several books (http://abiliooliveira.weebly.com/) \\ Email: olivirtual@gmail.com
}

\author{
Doi:10.5901/mjss.2013.v4n11p21
}

\begin{abstract}
About a third of the Portuguese population suffers from some form of rheumatic disease. Although the pathology in several persons is mild, these illnesses are chronic and incurable, have a progressive evolution, and the symptoms tend to become increasingly severe. Rheumatic illnesses frequently lead to major consequences for the person's life disturbing their social relationships, work and leisure. The present work is part of a larger project, and aim to understand how health and illness are represented among adults with rheumatic disease. The data was collected by free associations of words and processed through factorial correspondence analysis. Participants were questioned on what they think and feel about their health and illness. Their perceptions were analysed considering their age, sex and years of illness. The participants point out the illness as their major source of suffering and sadness, revealing they frequently feel discouraged, thinking they are different from other people. Women, more than men, express negative emotions and serious difficulties to maintain a healthy and independent lifestyle - they emphasize their functional limitations that seriously affect daily activities, in particular their mobility and housekeeping tasks. In general, men almost accept their health condition - it is as if they feel strong enough to face their illness and to find ways to improve their wellbeing. What the patients think and feel about their health and illness may convey important information for health professionals, working with patients with rheumatoid disease, in order to help them to improve strategies to deal with this population.
\end{abstract}

Keywords: chronic illness, health, rheumatic disease, pain, representations

\section{Introduction}

Rheumatic diseases ${ }^{1}$ can be considered as chronic, leading to irreversible changes or physical disabilities and, in most cases, requiring progressive adaptations according to the illness condition (Cruz \& Branco, 2001; Queirós, 2002).

The rheumatic diseases include over one hundred and twenty different diseases, their causes are frequently unknown and the most common are, first of all, osteoarthritis, and rheumatoid arthritis (RA). ${ }^{2}$ They are progressive and incurable, with an uncertain prognosis. Rheumatic diseases affect hundreds of millions of people around the world. In fact, about $12 \%$ of people over the age of twenty five years old are affected; and $60 \%$ of people over the age of sixty five years old have at least one joint with moderate to severe deformations.

Nowadays, about $38 \%$ of the Portuguese population - circa 2.7 millions - suffer from some form of these illnesses about 1.7 million men, and 970 thousand women. The incidence of many of these illnesses increases markedly with age (Lucas \& Monjardino, 2010; Faustino, 2003).

These diseases are usually characterized by pain, suffering and discomfort, degeneration of joints, alterations on the body, loss of mobility and autonomy, temporary or permanent disability, limitation and incapacity (Boyington, et al. 2008;

\footnotetext{
${ }^{1}$ Rheumatic diseases can be defined as functional alterations of musculoskeletal system without traumatic source (Queirós, 2002).

${ }^{2}$ Approximately $1 \%$ of the Portuguese population suffers from rheumatoid arthritis.
} 
Lucas \& Monjardino, 2010). Their impact is a heavy burden to any personal and social condition. They are the most common cause of severe long term pain and physical disability, significantly affecting the ability to perform several activities of daily living, the careers and the psychosocial status of all patients, as well as their families (Woolf \& A kesson, 2001).

Pain is the most prominent symptom in most people with arthritis, (Jackobsson \& Hallberg, 2002), and is among the most frequently reported, bothersome, and disabling symptoms described by patients with rheumatic diseases. The experience of pain is a primary determinant of disability in patients with rheumatic conditions (Edwards et al., 2006), affecting health and diminishing the patient's quality of life (Woolf \& Pfleger, 2003; Woolf, 2003). However, the impact felt by each person may be different considering the individual personality traits, beliefs, attitudes, ideology and values.

Among the more obvious physical limitations, patients report decreased capacity and dependence, primarily for carrying out activities such as walking, dressing, feeding and taking care of your personal hygiene.

The loss of mobility not only affects the realization of many activities of daily living but can also lead to gradual loss of independence of the individual.

Melanson and Downe-Wonboldt (2003) verified that the majority of patients with rheumatic diseases pointed their physical limitations as their main difficulties (e.g., physical limitations in relation to household chores, on driving or general mobility - mobility at home, in the community or using transport).

For example, the joints of the upper limbs, when compromised, can sometimes hamper the manipulation of the cutlery and the ability for cutting food; taking a simple cup of tea may become difficult and dangerous, especially if it is hard for someone hold the handle. For these reasons, some people get embarrassed when they eat in public, often leading them to isolation and non-participation in social events. It is not hard to imagine the impact of these diseases in domestic life (e.g., Allaire, Meenam \& Anderson, 1991).

A rheumatic disease restricts people's ability to perform social and occupational roles. It is the single greatest cause of disability in the elderly, with more than $53 \%$ of adults over the age of 65 years complaining because of this significant health problem (Pimm \& Weinman, 1998).

Moreover, the aging of the Portuguese population associated to the increase of rheumatic diseases triggers profound implications, specially, in plan's caring for older people, with rheumatic problems (Lucas \& Monjardino, 2010).

All rheumatic diseases may play important roles in shaping the cognitive, emotional and behavioural processes underlying each person's symptoms and adaptations to illness.

The diagnosis may be difficult, and people with rheumatic disease may experience unpredictable symptoms of severe pain, fatigue, stiffness, immobility, disability and disfigurement. This illness frequently leads to major consequences for the person's health and life affecting their social relationships, work and leisure.

The perception of pain, disability and dependence, influence the representations of disease and health (Miguel, Carvalho \& Baptista, 2000). In time, health's concept have been less focused on the absence of pain, illness or disability, giving emphasis to positive aspects (at personal and social levels), longevity and better quality of life. The health is linked to well-being and all human life experiences.

In fact, the concepts of health and disease are mutually influent and evolve simultaneously. They make part of our existence, emerging to us, in some degree, at different times (Ribeiro, 1998). Illness is centred on subjective experiences (including physical, psychological, emotional, social and cultural), has always some meaning, beyond indicating the absence of health. Somehow, health only becomes meaningful when confronted with illness, particularly with a chronic illness (Lindsey, 1996). ${ }^{3}$ Any illness is an experience of symptoms or suffering.

It is also important to realize 'how the sick person and the members of the family or wider social network perceive, live with and respond to symptoms and disability' (Skevington, 1996).

It urges to understand the perceptions of health and illness in patients with chronic or disabling conditions, such as the people suffering with rheumatic disease (Corbin \& Strauss, 1988). There are also expectations and beliefs about health, and health care effect, in the people's responses to illness and to the treatments that they subsequently receive (even to survive). Inevitably, this is linked to health and illness conceptualisations. In that way, living with a chronic illness leads to a variety of changes and consequences for everyday life (Corbin \&Strauss, 1987; Morse, 1997).

In this paper we approached the representations of health and illness in patients with chronic disease, especially with rheumatic disease. We considered some of people's beliefs, images and memories, about heath and illness, and the way these are associated to emotions and to the way of feeling (Thorne, 1993).

${ }^{3}$ The chronic diseases are defined as those who don't have known cure, causing general malaise and affecting the patient's everyday life. 


\section{Objectives}

The present work is part of a larger project, in order to understand how health and illness are represented among adults with rheumatic diseases. Briefly, we intended to:

- Understand how health and illness are represented among adult patients;

- Examine how these representations may differ according to the age, sex and degree of illness (time in years) of the participants;

- Verify how illness can interfere in the daily activities, and the way how patients usually feel.

\section{Method}

\subsection{Population}

This study was developed with a population of patients with rheumatic diseases ( $N=129), 64 \%$ women and $36 \%$ men, from 20 to 72 years old (21\% with ages between 20 to 39 years old, $53 \%$ with $40-64$ years old, and $26 \%$ with more than 65 years old); $24 \%$ of the participants are ill for less than five years, $38 \%$ suffer from this chronic disease for, at least, five years, and less than ten, and $38 \%$ of this population is ill for ten years or more.

\subsection{Variables}

As independent variables we considered gender/sex (men and women), age and the years of illness. The dimensions of health and illness, the way as illness could limit the daily activities, and the way the participants usually feel, were the dependent variables.

\subsection{Questionnaire and Procedure}

It was previously conducted a short focus-group, where we listened to what patients generally think and feel about pain, health and illness. After, having the indicators derived (from the dimensions obtained) from the focus-group, we developed a questionnaire including several open questions, such as:

- What do you think about your health?

- How do you feel about your health?

- What do you think about your illness?

- How do you feel about your illness?

- What changes did the disease implied in your daily activities?

These questions constituted different situations/stimuli, to which the participants responded individually and anonymously, with simple words or phrases. So, the data was collected by free associations of words, in a hospital (with outpatients), and was processed through factorial correspondences analysis.

\subsection{Ethical Considerations}

The participants were informed that their participation in the study was anonymous and voluntary. Accordingly, we obtained a written consent from each participant. The confidentiality and anonymity were assured by us.

\section{Results}

When we asked the participants for 'What do you think about your health?', their most frequent answers were poor health (to 26\%), threatened, fragile, malaise and affected or impaired (cf. Table 1). Health is perceived as something that compromises the lives of the participants, as a real threat, making them feel, above all, weak, uneasiness or harmed.

The conceptions of women and men differ in some issues. Women expressed more negative thoughts about their health, while men almost seem to accept their condition, considering they are strong enough to deal with it. Particularly, women affirm to be delicate and fragile, feeling unbalanced by health problems.

Men, more than women, prefer to think that their health is reasonable, although they recognize their health as committed and precarious. 
Both age and the year in which the disease was diagnosed, seem to have no effect on the perceptions of health. Rheumatic diseases imply malaise and bothering changes in health and in life, for all the participants/patients. The experience of living with rheumatic disease can truly change the representations of health, and the patients realize that their health is very committed.

Table 1. Classification of the most frequent words from the answers to: 'What do you think about your health' and 'How do you feel about your health'

\begin{tabular}{cc}
\hline Thoughts about health & Feelings about health \\
\hline Poor & Sadness \\
Threatened & Adapted \\
Fragile & Dependent \\
Malaise & Well / Unhappy \\
Affected & Hopeless \\
Impaired & Tranquil \\
$\ldots$ & Limited \\
& Inability \\
\hline
\end{tabular}

In sequence of the question 'How do you feel about your health?', we obtained more negative emotions and feelings (sadness, adapted, dependent, unhappy, hopeless, limited, inability, fear) than positive (well, tranquil). When the patients represent health they always think about their illness and of what it emotionally implies for them. The concepts of health and illness are often mixed. In fact, the concept of health is affected by a illness state, characterized by a condition of pain or suffering, perceived as unbearable, uncomfortable and embarrassing, requiring some dependence from others, and also fear of the future. In some cases, patients divulge a feeling of adaptation, conveying a certain well-being and tranquillity (cf. Table 1).

Men reveal a more positive view of health than women, showing a greater will to have some expectation in their progressive condition and to keep calm, accepting their state and striving for adaptation and to be comfortable, despite the fear of what may happen to them, if they cannot control the symptoms or their reactions. Women feel more sad, unmotivated and dependent on their care and needs. For the younger participants, it is natural expressing a need for adaptation and feeling optimistic, in contrast with the others that repeatedly complain for their dependency and uncertainty on their future.

The most usual answers to 'What do you think about your illness?', refer to the illness as a personal situation that became chronic. Participants emphasize that the illness causes pain, disability, limitations, discomfort, implying relevant changes in their routines or daily activities - it may become complicated and uneasy accepting the situation, anyone would have difficulties in the unavoidable process of adaptation (cf. Table2).

Women put the accent on the disease as a very painful process, at all levels, leading to disability or dependency of others; men give more significance to the consequences of the illness at a physical level, thinking on the deformation of the body or incapacity, particularly to work.

The older the patients are the greater is the tendency to represent the illness negatively - a patient, who suffers from this kind of illness since a long time, denotes more complaints about the dependence and the changes he needs to assume on his life.

The most recurrent emotion, or sentiment, derived from 'How do you feel about your illness?', was dependent, followed by adapted, hopeless, sadness, inability, fear. The participants feel malaise, revealing a strong discomfort with the suffering and disability the disease implies (cf. Table 2).

The responses less negative (or neutral) are adapted/adaptation and acceptance, mainly because men have a more positive perception of health than women, showing a need for adaptation and some hope on the future; women feel more ill, apprehensive, misunderstood, discouraged and alone. Younger people are more optimistic, showing feelings of hope and acceptance; the older tend to complain for their dependency, sadness and incomprehension by family and friends. 
Table 2. Classification of the most frequent words from the answers to: 'What do you think about your illness' and 'How do you feel about your illness'

\begin{tabular}{cc}
\hline Thoughts about illness & Feelings about illness \\
\hline Chronic & Dependent \\
Permanent & Adapted \\
Disabled & Hopeless \\
Limited & Sadness \\
Painful & Inability \\
Need to make changes & Fear \\
Complicated & Revolted \\
$\ldots$ & Acceptance \\
& Malaise \\
\hline
\end{tabular}

Faced with the question 'What changes did the disease implied in your daily activities?', the participants showed that they feel limited or affected by the rheumatic disease, even in the most common daily needs and performance, just as walking, household tasks and professional tasks, personal hygiene, dressing up, getting up or combing up (cf. Table 3).

All of the patients, regardless of gender, age and years of disease duration, revealed that the disease interfere with their routines, especially in their work, underlying that since they became more ill they feel slower, inefficient or limited when performing many daily tasks, mainly due to the constant or frequent pain they feel. So, most of them disclose sad feelings, discouragement and even, in some cases, depression symptoms. However, there are still patients that really make an effort to maintain hope and optimism about their situation.

Women, more than men, feel misunderstood, and alone, lamenting, above all, from the difficulty to correspond to the household tasks. Men have more confidence in the efficacy of the treatments and medications, and on the healthcare professionals' capacity, to help them, in the moments they need more.

Table 3. Classification of the most frequent words from the answers to: 'What changes did the disease implied in your daily activities?'

\begin{tabular}{c}
\hline Changes in daily activities \\
\hline Walking \\
Household tasks \\
Professional / Work \\
Personal hygiene \\
Dressing up \\
Getting up \\
Combing up \\
Feeding \\
Climbing up \\
Sleeping \\
$\ldots$
\end{tabular}

\section{Discussion}

The rheumatic diseases are devastating to the lives of individuals either by direct impact on daily activities, as by the implications on family, profession and at a social level. The limitation or disability to do some tasks may also imply a strong psychological impact associated to feelings of failure, frustration and depression (e.g. Gaião, 1990).

With no cure for chronic conditions, especially in the case of osteoarthritis and rheumatoid arthritis (the medical treatments are only partially effective), it urges to explore the process that mediates between the health and the disease perception, among these patients. Some of them know how to manage their disease very successfully. Our understanding of how they do it, will help us to develop interventions to assist people who show more difficulties.

It is also important to understand some shared beliefs; these have implications on the interactions between health professionals and patients. The person with rheumatic disease may regard pain as the most important indication of the seriousness of her health or illness state, while health professionals may view inflammation and joint damage as more 
important indication of disease severity. Such difference, between these two perceptions, may produce some misunderstanding or disrupt communication.

The rheumatic disease and particularly the pain associated to it, is accompanied by a great personal suffering, with great repercussions on individual, family, social and professional level. Being a multidimensional phenomenon, this illness affects a person in different areas: cognitive, emotional, behavioural and physical. Living with pain implies changes in the way a person represents the body and herself.

Regardless of their age and the moment when the disease was diagnosed, most participants showed difficulties to live with this disease, which makes them feel sad, disillusioned and discouraged.

Women described with more precision the severe physical and functional problems of living with a rheumatoid disease. They expressed more suffering, and negative emotions, complaining about limitations and disabilities and revealing a more negative perception of illness, than men.

Women emphasized the difficulties to maintain health and independency, considering that pain and functional limitations affect several daily activities, like work, mobility and housekeeping.

With regard to household tasks, limitation of joint function and disability can lead to loss of dexterity, preventing the patient to perform activities such as cooking, lift the pans, peel vegetables, turn on the stove, opening and closing taps and packaging, as well how to use some appliances (Sturdy, 1998).

The physical pain and emotional pain are deeply interconnected, and both are immeasurable and intimate for each human being. Patients with a rheumatic disease seem to feel different from others, without a chronic disease. This reveals part of the psychological impact of this kind of illness.

\section{Conclusion}

The notion of health is linked to pain and suffering, generally considered as unbearable, causing dependence on others and fear of the future, as well as sadness and discouragement (Sá \& Oliveira, 2011). However, some patients show ability to accept or adapt, revealing relative well-being, and tranquillity. Rheumatic diseases affect a significant part of the population and have a strong social impact, on the public health, at a professional level and even in economic-financial terms.

The rheumatic patients are faced with problems that impose various restrictions, causing them to have low selfesteem, dependence on others and social isolation. These problems are often portrayed by the uncertainty of the disease, and the significant changes in the way of living, involving rebuilding the everyday and develop strategies to face personal difficulties and social relations.

Pain becomes strongly meaningful when is constantly present - even if its intensity varies over time. It makes us question the hope and all that we are. In face of it, patients may reply with courage, adaptation, fear or uncertainty. Pain and suffering affect the individual, in all his areas of action. So, the ill condition cannot be resolved only at a physical level, or by a magical way, but rather with the knowledge that healthcare professionals have about each person affected.

Knowing also the functional and emotional difficulties, and the limitations of the patients, health professionals may have a better understanding of patients' priorities and improve their strategies to deal with them, providing the adequate care to help them facing the everyday life, contributing as much as possible for their wellbeing.

In this sense, it is urgent to understand the representations of health and illness among people with rheumatic diseases. Thereby we intend to contribute to understand the condition of living with a rheumatic disease, and of how we may find ways to help someone in suffering, to face the daily tasks and activities more positively and with more hope.

\section{References}

Allaire, S., Meenam, R. \& Anderson, J.J.(1991). The impact of rheumatoid arthritis on the household work performance of women. Arthritis Rheumatoid, 6, 669-678.

Boyington, J., DeVellis, R., Shreffler, J., Schoster, B. \& Callahan, L. (2008). Factor Structure of the Arthritis Body Experience Scale (ABES) in a U.S. Population of people with Osteoarthritis (OA), Rheumatoid Arthritis (RA), Fibromyalgia (FM) and Other Rheumatic Conditions. The open Rheumatology Journal, 2, 64-70.

Corbin, J. \& Strauss, A.(1988). Unending Work and Care Managing Chronic Illness at home. San Francisco: Jossey-Bass.

Corbin, J. \& Strauss, A. (1987). Accompaniments of chronic illness. Changes in body, self, biography, and biographical time. Research in the Sociology of Health Care, 6, 249-281.

Cruz, M. \& Branco, J. (2001). Paradigma das doenças reumáticas crónicas. Tecnologia Médica. Lisboa: 2, pp. II-XI.

Edwards, R., Bingham, C., Bathon, J. \& Haythorntnwaite, J. (2006). Catastrophizing and pain in Arthritis, Fifromyalgia, and others 
Rheumatic Diseases. Arthritis \& Rheumatism, 55 (2), 325-332.

Faustino, A. (2003). Aspectos da reumatologia em Portugal - Relevância epidemiológica das doenças reumáticas em Portugal. Revista Portuguesa de Reumatologia e Patologia Osteoarticular, 13, 4-6.

Gaião, L. (1990). Impacto médico, económico e social dos reumatismos na 3a Idade. Acta Reumatológica Portuguesa, 54, 1, 3-9.

Jackobsson, U. \& Hallberg, I. R. (2002). Pain and quality of life among older people with rheumatoid arthritis and/or osteoarthritis: A literature review. Journal of Clinical Nursing, 11, 430-443.

Lindsey, E. (1996). Health within illness. Journal of Advanced Nursing. Setembro, 24 (3), 465-472.

Lucas, R. \& Monjardino, M. (2010). O estado da Reumatologia em Portugal. Porto: Observatório Nacional das Doenças Reumáticas.

Melanson, P. \& Downe-Wamboldt, B. (2003). Confrontig life with rheumatoid arthritis. Journal of Advanced Nursing, Oxford, 42 (2), $124-$ 133.

Miguel, A., Carvalho, M. \& Baptista, A. (2000). Ajustamento emocional, saúde e qualidade de vida em jovens adultos. Lisboa: Instituto Superior de Psicologia Aplicada.

Morse, H. (1997). Responding to threats to integrity of self. Advances in Nursing Sciences, 19, 21-36.

Oliveira, A. (2011). O Desafio da Vida. Lisboa: Coisas de Ler.

Pimm, J. \& Weinman, J. (1998). Applying Leventhal's Self Regulation Model to Adaptation and Intervention in Rheumatic Disease. Clinical Psychology and Psychotherapy, 5, 62-74.

Queirós, M. (2002). Reumatologia: clínica e terapêutica das doenças reumáticas, vol 2. Lisboa: Lidel.

Queirós, M. (2002). Reumatologia: fundamentos. Lisboa: Lidel.

Ribeiro, J. (1998). Psicologia e Saúde. Lisboa: Instituto Superior de Psicologia Aplicada.

Sá, C. \& Oliveira, A. (2011). 'What do you think about your body and your pain?' In Andrzej Danczak and Nicola Lazenby (Ed), Pain Management, Expression, Interpretation. Oxford: The Inter-Disciplinary Press, pp. 11-21.

Skevington, S. (1996). Psychology of Pain. Chichester: Wiley.

Strudy, C. (1999). Assessing rheumatic patients. In Jackie Hill (Ed.), Rheumatology Nursing. A creative approach. London: Churchill Livingstone, pp. 77-93.

Thorne, S.(1993). Negotiating health care. The social context of chronic illness. California: Sage Newbury Park California.

Woolf A. \& Akesson, K. (2001). Understanding the burden of musculoskeletal conditions. The burden is huge and not reflected in national health priorities. British Medical Journal, 322, 1079-80.

Woolf, A. \& Pfleger, B. (2003). Burden of major musculoskeletal conditions. Bulletin of the World Organization. 81(9), 646-654.

Woolf, A. (2003). The Bone and Joint Decade. Strategies to reduce the burden of diseases: the Bone and Joint Monitor Project. The Journal of Rheumatology, 30, supplement 67, 6-9. 